\title{
Microstructure of cross-linked high densification network and strengthening mechanism in cold-sprayed Ti-6Al-4V coating after heat treatment
}

\author{
Hongxia Zhou ${ }^{1,2}$, Chengxin $\mathrm{Li}^{1 *}$, Xiaotao Luo ${ }^{1}$,Guanjun Yang ${ }^{1}$, Tanvir Hussain ${ }^{3}$, Changjiu $\mathrm{Li}^{1}$ \\ ${ }^{1}$ Sate Key Laboratory for mechanical Behavior of Materials, School of Materials Science and Engineering, Xi'an Jiaotong \\ University, Xi'an, Shaanxi 710049, China
}

${ }^{2}$ Qinghai Provincial Key Laboratory of New Light Alloys, Qinghai Provincial Engineering Research Center of High Performance Light Metal Alloys and Forming, Qinghai University, Xining 810016, China.

${ }^{3}$ Faculty of Engineering, University of Nottingham, Nottingham, NG7 2RD, UK

\begin{abstract}
In this study, Ti-6Al-4V (TC4) coating was prepared using an in-situ shot peening-assisted cold spraying technology in which large shot peening particles were mixed with TC4 spraying powders to prepare the deposit. To improve its strength and toughness, the coating was heat-treated at $600-1000{ }^{\circ} \mathrm{C}$ in vacuum. The results demonstrated that the microstructure of the as-sprayed coating exhibited a special structure that was denser at the regions tamped by the shot peening particles and porous at the nontamped regions. When the coating was heat-treated at $800{ }^{\circ} \mathrm{C}$ and $1000{ }^{\circ} \mathrm{C}$, the interface between the particles had largely disappeared and the local pores had interconnected with each other due to thermal diffusion and recrystallization. The coating hardness decreased slightly after annealing at $600{ }^{\circ} \mathrm{C}$ and $800{ }^{\circ} \mathrm{C}$ due to the released strain hardening effect. The bonding strength of the coating after annealing improved in comparison with that of the as-sprayed coating. The tensile strength of the coating improved significantly under annealing at $800{ }^{\circ} \mathrm{C}$. A cross-linked high densification network was formed after annealing due to the effect of in-situ shot peening, which served as a reinforced framework and enhanced the strength of the coating.
\end{abstract}

\section{Keywords}

Cold spraying; Ti-6Al-4V; In-situ shot peening;cross linked high densification networks.

\section{Introduction}

Titanium and its alloys are employed in the aerospace and marine industry owing to their high specific strength and corrosion-resistance properties. TC4 is the most common alloy used, which accounts for approximately $60 \%$ of the total titanium used [1,2]. However, the cost to extract and manufacture titanium and its alloys limit their affordability in many low-tech applications due to prohibitively expensive production processes that require a controlled atmosphere such as vacuum melting $[3,4]$; the absence of oxidation through cold gas dynamic spray (cold spray) process makes this technology a cost-effective alternative in direct fabrication of titanium products [5]. Many reports confirmed that titanium oxides were not generated in the deposit under low process temperatures, which are different from the conventional thermal spray methods [6-11], and thus making titanium an affordable choice for wider industrial applications.

Cold spraying is an emerging powder processing method that involves material build-up of solid state particles; it has been a member of the thermal spray family since its discovery in 1980. A dense 
coating can be fabricated using cold spray technology for highly deformable face center cubic (FCC) alloys, such as aluminum and copper [12-16]. However, Ti and its alloys are less amenable to cold spray processing owing to their high strength and limited capacity for plastic strain, making it difficult to obtain a dense coating. The porosity of the cold-sprayed TC4 coatings has been reported as $\sim 10-30 \%[5,17-19]$ and has largely resulted in depositions with poor properties [17,20,21]. The deposition of Ti and Ti alloy coatings with helium as the propellant gas was found to be effective [22]; however, it was unsuitable for industrial applications as it was expensive.

In cold-sprayed coating, there is an in-situ shot peening effect in which the previously deposited particles are hammered by the following particles [23]. Based on this effect, it is considered that larger deformation of less plastic metal coatings such as Ti and its alloys can be achieved by adding other shot peening particles into the spray powder. When the large shot particles and TC4 particles are sprayed onto the substrate at the same time, the shot particles rebound as they do not reach the supposed critical velocity, and the impact before the rebound tamps the deposited TC4 particles and deforms them again. In-situ shot peening in a cold spraying process provided a new way to prepare dense TC4 coatings [24]. In our previous research [25], we obtained dense TC4 coating with high gas temperature combined with in-situ shot peening. The results indicated that, although the deformation of TC4 particles was effectively improved at the tamped regions caused by the shot-peening particles, the improvement of mechanical properties was limited due to the weak bonding between the TC4 particles. To obtain a high-performing titanium alloy component by cold spraying, it was not only enough to enhance the particle deformation and reduce the porosity, but was also necessary to improve the bonding state between the particles, which had an important influence on its mechanical, thermal and electrical properties [26-29].

Post-spray heat treatment has been found to be an effective approach to improve the bonding state between the particles and to recover the intrinsic ductility and serviceability of the deposited materials [30-32]. Post-spray annealing at elevated temperatures of $600-800{ }^{\circ} \mathrm{C}$ [33], 840-850 ${ }^{\circ} \mathrm{C}$ [17], and $954{ }^{\circ} \mathrm{C}$ [21] has shown to increase the metallurgical bond area between particles. Consequently, the bonding strength between the coating/substrate and particle/particle was enhanced to some extent and the properties of the deposit were improved due to changes in the microstructure. Vo et al. [34] achieved an increase of up to $460 \mathrm{MPa}$ in tensile strength with a failure strain of $5.5 \%$ after the heat treatment of the TC4 coating at $1,000{ }^{\circ} \mathrm{C}$ with a nitrogen inlet gas. This strength was similar to the strength of the He-sprayed coating under the as-sprayed conditions. Hence, cold spraying with nitrogen gas combined with post-spray heat treatment is an effective path to reduce the production cost of Ti and Ti alloy coatings.

In this study, we investigated the coatings produced using an in-situ shot peening-assisted cold spraying process with nitrogen as propellant gas to evaluate the potential of cold spray processing for titanium alloy applications. Post-spray heat treatment was performed to improve the mechanical properties. The mechanical properties were determined by the microhardness, bonding strength, and tensile testing, while the microstructural development was characterized by fracture morphology analysis.

\section{Experimental}

\subsection{Materials}

Gas atomized spherical TC4 powder (Raymor Industries Inc., Boisbriand, Canada), which was mechanically mixed with 70 vol.\% $1 \mathrm{Cr} 18$ stainless steel shot-peening particles, was used as the starting 
powder. The particle size distribution was measured using the laser diffraction method (Toshima MFG Co., Ltd, Japan). The sizes of TC4 and stainless steel particles ranged from 15 to $30 \mu \mathrm{m}\left(\mathrm{d}_{0.5}=22.6 \mu \mathrm{m}\right)$ and from $125 \mu \mathrm{m}$ to $300 \mu \mathrm{m}\left(\mathrm{d}_{0.5}=181 \mu \mathrm{m}\right)$, respectively. The morphology and size distribution of the as-received powders are shown in Fig. 1.

TC4 coatings were deposited onto commercial TC4 bulk substrate with the aim of repairing components of the same alloy. The chemical composition of the substrate is shown in Table 1. Prior to spraying, the substrate was degreased using acetone and grit-blasted with grit alumina to obtain a rough surface.

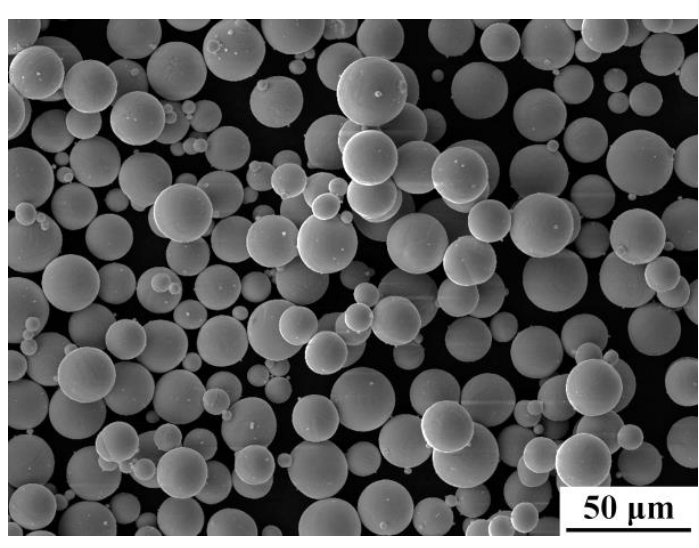

(a)

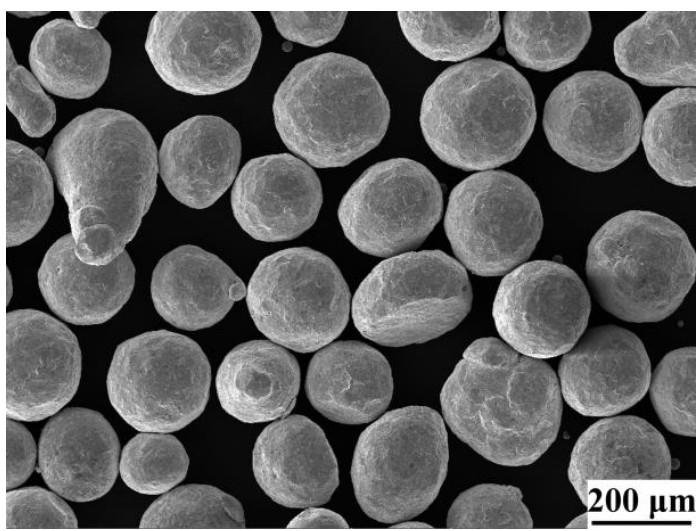

(c)

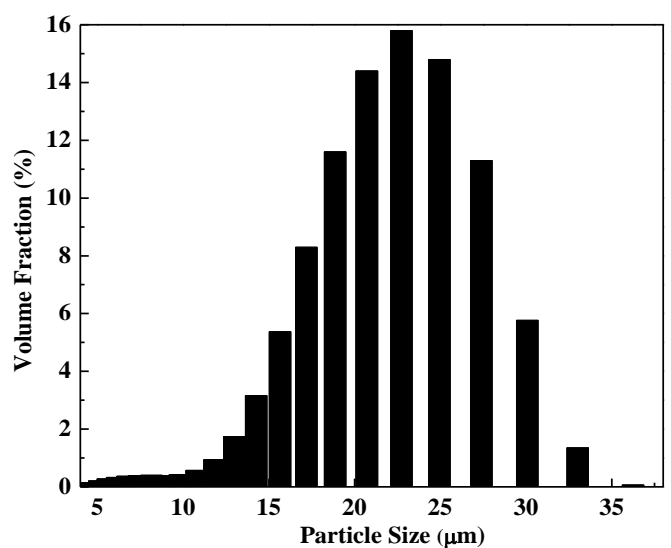

(b)

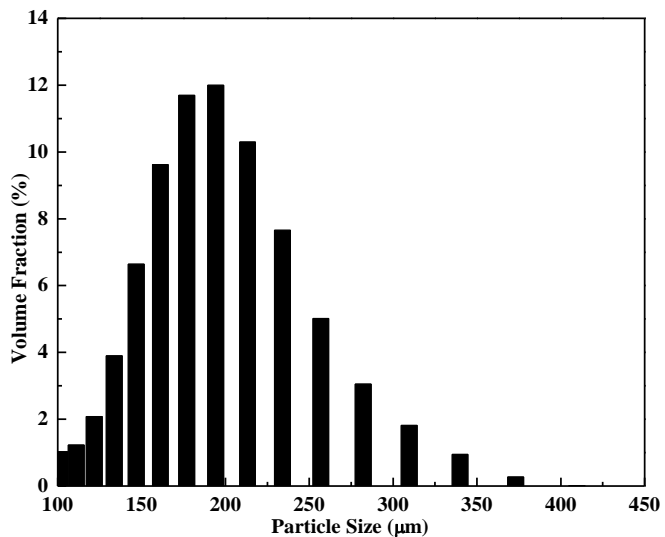

(d)

Fig.1 Morphologies and size distribution of TC4 ( $a$ and b) and stainless steel particles (c and d)

Table 1 Chemical composition of TC4 substrate (wt. \%)

\begin{tabular}{ccccccc}
\hline Element & $\mathrm{Ti}$ & $\mathrm{Al}$ & $\mathrm{V}$ & $\mathrm{Fe}$ & $\mathrm{O}$ & $\mathrm{H}$ \\
\hline Content & Balance & 6.43 & 4.13 & 0.141 & 0.13 & 0.008 \\
\hline
\end{tabular}

\subsection{Coating preparation and heat treatment}

The coating was prepared using an in-house cold spray system. Nitrogen was used as the inlet gas 
with a gas temperature of $680{ }^{\circ} \mathrm{C}$ and a gas pressure of $2.5 \mathrm{MPa}$. The scan speeds were $40 \mathrm{~mm} / \mathrm{s}$ and 100 $\mathrm{mm} / \mathrm{s}$ (only for the sample used in the bonding strength test), stand-off distance was $20 \mathrm{~mm}$, and the powder feeding rate was $50 \mathrm{~g} / \mathrm{min}$. The thickness of the coating was about $2.5 \mathrm{~mm}$ for preparing the specimen for tensile testing ( $300 \mu \mathrm{m}$ of the specimen for adhesion testing).

The coatings were sealed in a quartz tube in a vacuum of $7 \times 10^{-4} \mathrm{~Pa}$ to avoid oxidation. They were heat-treated in a box furnace at a heating rate of $5{ }^{\circ} \mathrm{C} / \mathrm{min}$ over a wide range of temperatures of $600{ }^{\circ} \mathrm{C}$, $800{ }^{\circ} \mathrm{C}$, and $1,000{ }^{\circ} \mathrm{C}$ for $2 \mathrm{~h}$, and then air cooled to room temperature. To compare the evolution of microstructure, the coating was also heat-treated at $700{ }^{\circ} \mathrm{C}$ and $900^{\circ} \mathrm{C}$ for $2 \mathrm{~h}$.

\subsection{Characterization}

The microstructure of the as-sprayed and heat-treated coatings was characterized using field emission scanning electron microscopy (FESEM; TESCAN MIRA 3, Czech). For the observation of morphology, the sawed samples were ground using SiC abrasive papers (600-2000 grit) and polished with colloidal silica $(0.02 \mu \mathrm{m})$ suspensions, followed by ultrasonic cleaning.

The porosities of the specimens before and after the heat treatment were measured from the cross-section of the coatings based on the image analysis method. For each sample, ten SEM images recorded at $1000 \times$ in backscattered electron mode were analyzed to obtain an average porosity level. The microstructure of the cross-section of the heat-treated coatings was examined using electron back-scattered diffraction (EBSD). The EBSD specimens were prepared by electrochemical polishing. EBSD maps were processed using an Oxford HKL Channel 5 EBSD Tango software module. The transmission electron microscope (TEM) investigations were conducted using a field emission transmission electron microscope (JEM-200CX, JEOL, Japan) operating at $200 \mathrm{kV}$. For the TEM sample preparation, a disc specimen with a $3 \mathrm{~mm}$ diameter was wet polished to a thickness below $50 \mu \mathrm{m}$ using $\mathrm{SiC}$ abrasive papers up to 2400 grit. Subsequently, it was further thinned to below $20 \mu \mathrm{m}$ using twin jet electrolytic thinning. Bright-field imaging techniques were used to obtain the microstructure of the coating after the heat treatment.

The microhardness of the samples was measured from the cross-section of the coating in a polished state under a normal load of $300 \mathrm{~g}(2.94 \mathrm{~N})$ using a Vickers microindenter with ten indentation measurements per sample to obtain the average hardness.

The bonding strength of the coatings before and after the heat treatment was measured using a tensile test machine (Instron 5569, America) according to the ASTM C633 standard. The top surfaces of the cylindrical samples with a diameter of $25.4 \mathrm{~mm}$ were coated with TC4 coatings and then glued to the respective counter-bodies of the same size using E7 epoxy glue. The maximum strength of the glue was approximately $60 \mathrm{MPa}$. Adhesion tests were performed on three specimens per group for statistical reasons.

A nonstandard tensile specimen with $2 \mathrm{~mm}$ thickness, machined by wire cutting, was used to test the tensile properties of the coatings, where the width of the gauge section and the total length were $5 \mathrm{~mm}$ and $60 \mathrm{~mm}$, respectively (Fig. 2(b)). The in-plane tensile properties were measured using a tensile test machine (Instron 5569, America) according to the ASTM E8M standard. The fractured surfaces of the tensile specimen were also observed with SEM. 


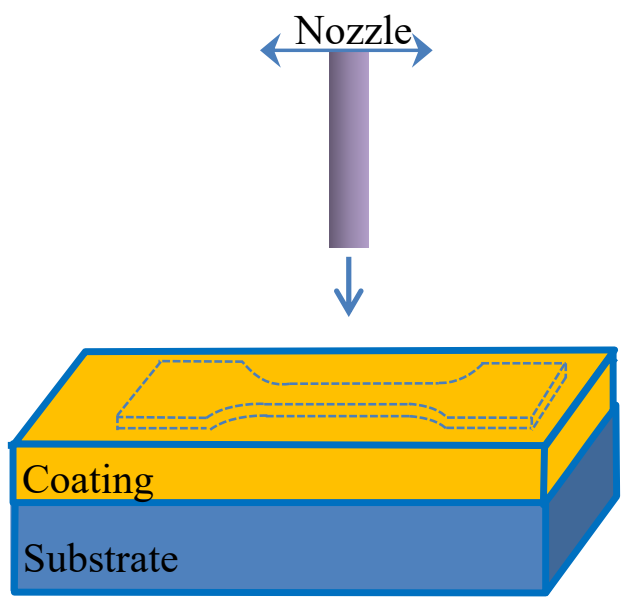

(a)

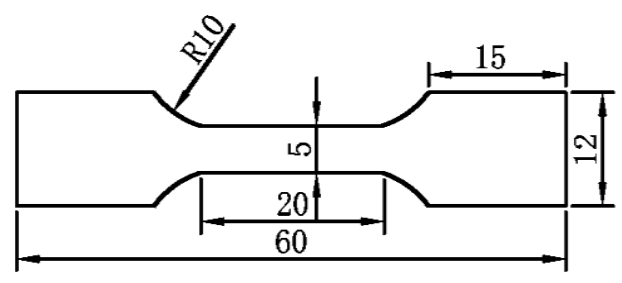

(b)

Fig. 2 Schematic representation of the samples machined from the directly fabricated cold-sprayed TC4 coating(a) and the dimension of the tensile samples(unit: $\mathrm{mm})(\mathrm{b})$

\section{Results}

\subsection{Microstructure}

The microstructure of the coating before and after the heat treatment is shown in Fig. 3. it is observed that, especially in the area where there was no impact of the shot-peening particles, the interface between the as-sprayed particles is mostly visible, the spherical particles are less deformed and there are pores between the particles. The yellow line indicates the craters left by shot peening particles, and the deformation of the particles at the bottom of the craters (This is later referred to as the tamped region) was more severe as compared to those at the other regions. For calculation of the flattening ratio of single splats, the ratio of the larger dimension of the splats to the diameter of a circle of equivalent area was calculated from the splat [35]. According to statistical result, the flattening ratio in the tamped and nontamped area was 3.88 and 1.27, respectively. This showed that the peening effect of stainless steel particles improved the deformation of the particles effectively, and it was almost equivalent to the value of TC4 obtained using high temperature spraying with helium as inlet gas [22]. Moreover, it is worth mentioning that the shot peening particles did not cause a serious erosion in the as-sprayed coating, and the deposition efficiency of the coating reached $70 \%$, which was consistent with the values reported in the literature $[36,37]$.

There was no obvious change in the coating after the heat treatment at $600{ }^{\circ} \mathrm{C}$. The morphology of the cross-section of the coating and the structure of the pores did not change significantly in comparison with that of the as-sprayed coating. The particle interface and the shot peening craters (indicated by yellow lines) were still distinguishable. However, after the heat treatment at $800{ }^{\circ} \mathrm{C}$, the interface between the particles had largely disappeared mainly due to recrystallization (according to our previous research [38], the recrystallization of cold-sprayed TC4 coatings occurred at $700{ }^{\circ} \mathrm{C}$ ). This indicated that the diffusion of the coating was significantly enhanced at this temperature, and it was difficult to identify the regions 
tamped by the large shot-peening particles. When the temperature was further increased to $1000{ }^{\circ} \mathrm{C}$, the structure of the coating changed further and the particle interface disappeared completely. It seemed that a large number of new phases grew from the inside to the surface, and the local pores had interconnected with each other and expanded at the same time. Once the surface of the coating was polished, the backscattered electron method was used to analyze the microstructure of the coating after the heat treatment. From Fig. 4, a slightly blended particle boundary is observed after the heat treatment at $600{ }^{\circ} \mathrm{C}$, and most of particle interfaces were healed after the heat treatment at $800{ }^{\circ} \mathrm{C}$ and $1000{ }^{\circ} \mathrm{C}$. In contrast, after the heat treatment at $800^{\circ} \mathrm{C}$, a distinct two-phase structure was observed, which became more evident when the temperature was increased to $1000{ }^{\circ} \mathrm{C}$. From the local EDS analysis, it is observed that the light-colored phase at region A contains $\mathrm{V}$ and Fe elements. Because both of them belong to the $\beta$ phase stable element, it was speculated that region A represents the $\beta$ phase and region $B$ represents the $\alpha$ phase.
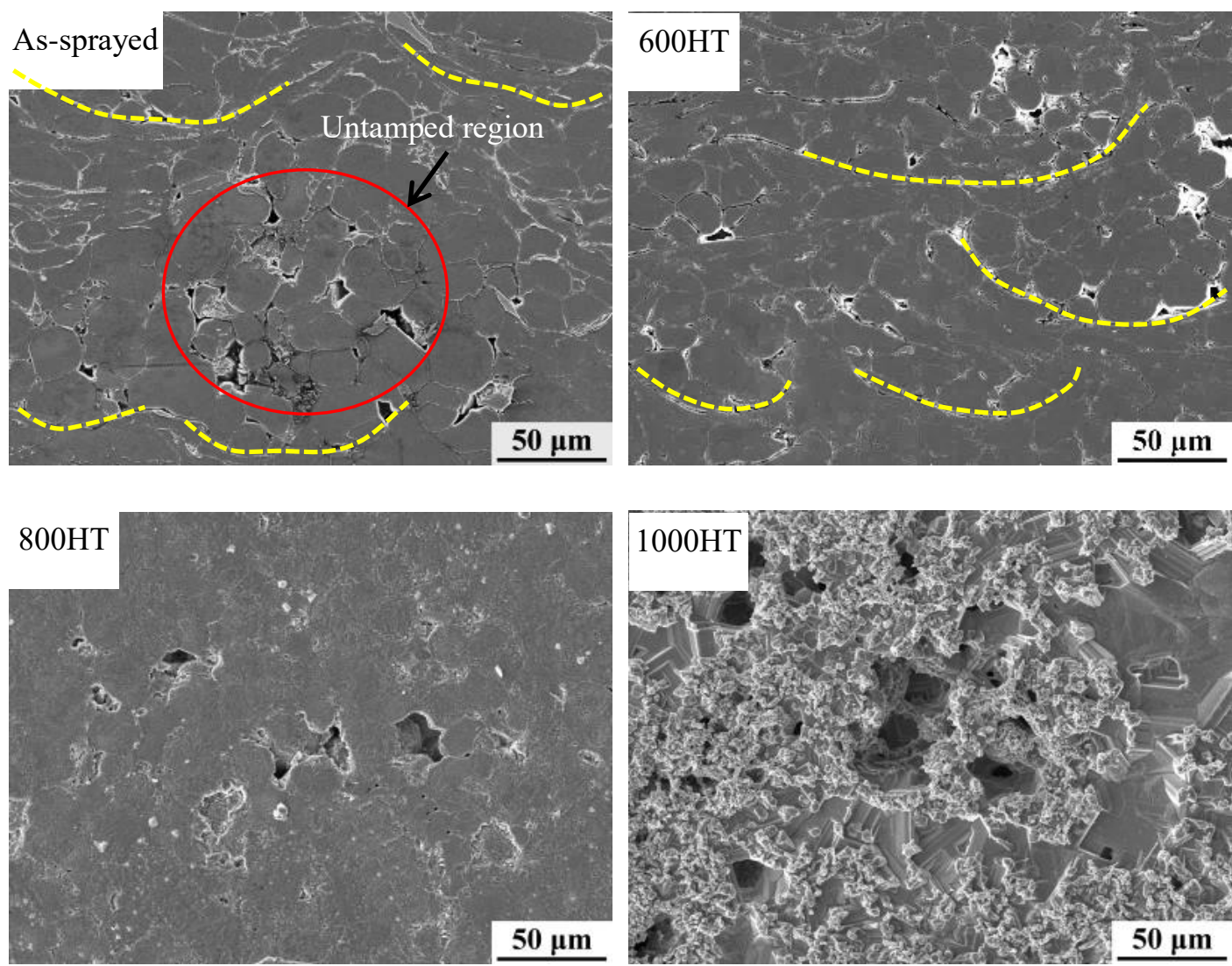

Fig. 3 Cross-sectional morphology of the coating before and after heat treatment

(The coatings heat treated at $800^{\circ} \mathrm{C}$ and $1000^{\circ} \mathrm{C}$ were not polished) 

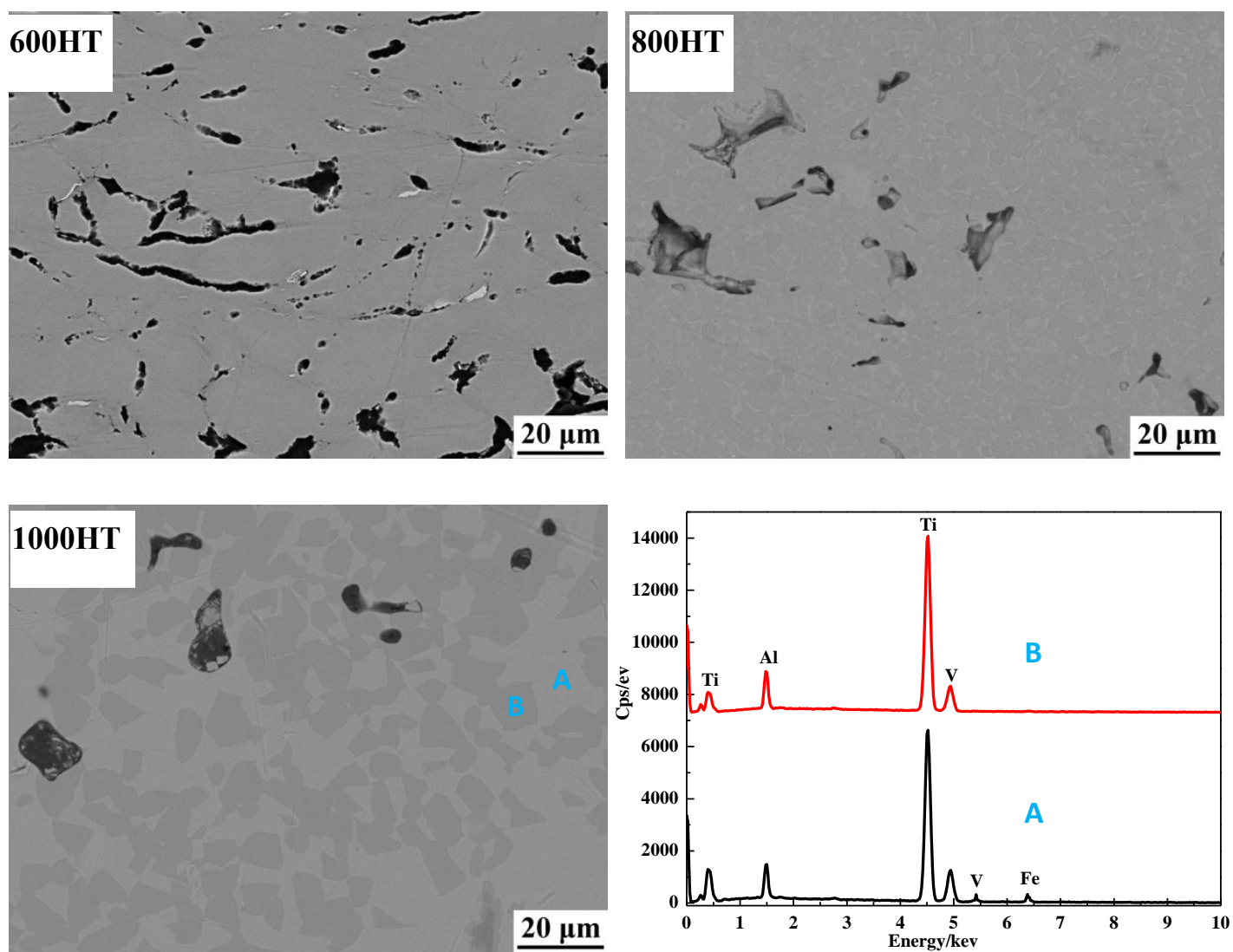

Fig.4 Cross-sectional morphology of the coating after heat treatment and local EDS analysis

\subsection{Mechanical Properties}

\subsubsection{Microhardness}

The microhardness of the coating before and after the heat treatment are shown in Fig. 5. Owing to the special microstructure of the coating prepared using in-situ shot-peening-assisted cold spraying, the microhardness can be divided into two tiers i.e., tamped regions and nontamped regions, and the two can be distinguished in the as-sprayed coating and the coating heat-treated at $600{ }^{\circ} \mathrm{C}$ due to the limited diffusion. However, it is almost indistinguishable in the coating heat-treated at $1000{ }^{\circ} \mathrm{C}$ due to the enhanced diffusion as indicated by the microstructure in Fig. 3. It can be seen that the values in the regions near the craters, caused by the shot-peening particles, were higher than those away from them in both as-sprayed coatings and coatings heat-treated at $600{ }^{\circ} \mathrm{C}$. On comparing the two, a slight decrease was found in both tamped and nontamped regions of the coating heat-treated at $600{ }^{\circ} \mathrm{C}$. Moreover, the coatings heat-treated at $800{ }^{\circ} \mathrm{C}$ exhibited a decrease as well, which was in agreement with earlier reports [39-42]. The decrease in hardness after heat treatment was associated with the microstructural softening through static recovery mechanisms such as softening of the deposited layers and elimination of dislocation density [39-42]. Conversely, when the temperature was increased to $1000{ }^{\circ} \mathrm{C}$, the hardness increased, which was comparable to that of the as-deposited coating. This probably resulted from the formation of an $\alpha$ 'martensitic phase in the coating $[43,44]$. As shown in Fig. 6 , there are a large number of short needle-like phases that appearedafter the heat treatment at $1000{ }^{\circ} \mathrm{C}$, which is supposedly the $\alpha$ 'martensitic phase. Owing to the high hardness of the martensite phase, an increase in the microhardness of the coating was exhibited. 


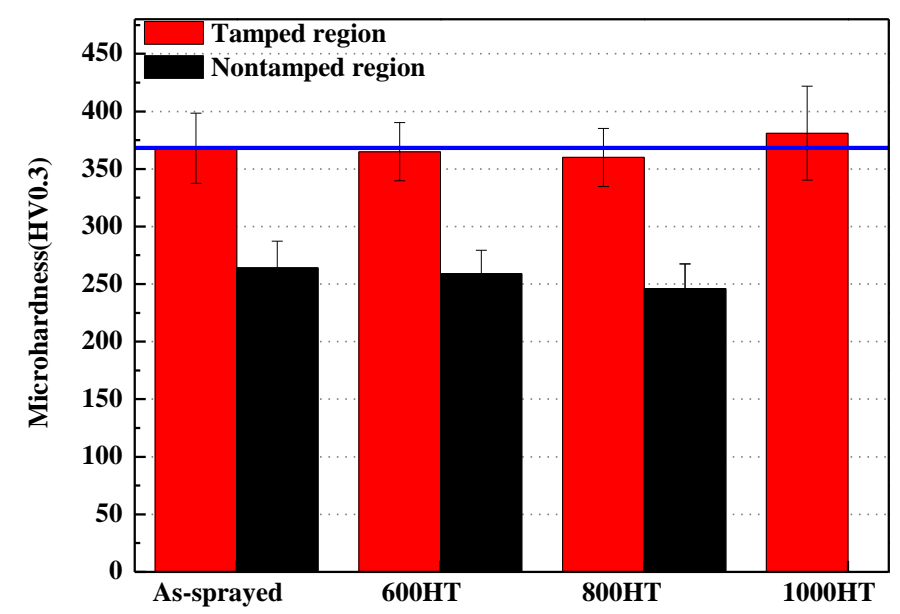

Fig.5 Microhardness of as-sprayed and heat-treated coatings

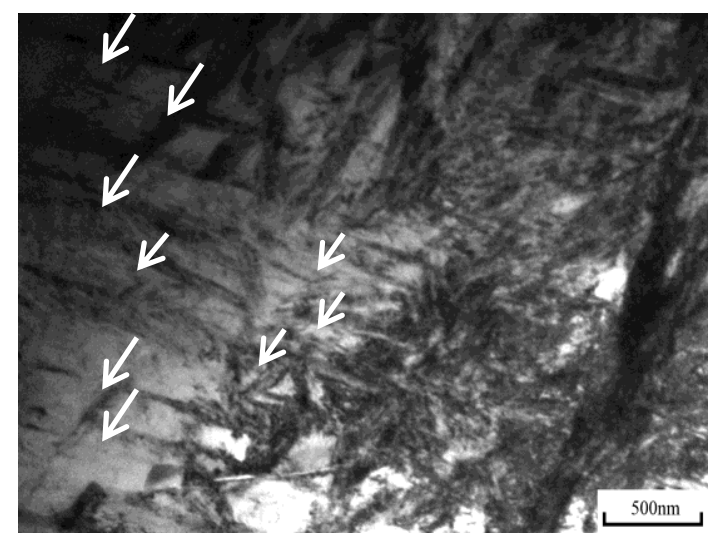

Fig. 6 TEM bright field of the coating after $1000^{\circ} \mathrm{C}$ heat treatment

(The white arrows pointed to the $\alpha$ 'martensitic phase)

\subsubsection{Adhesion strength}

Fig. 7 shows the pull-off adhesion strength before and after the heat treatment. As expected, the heat treatment caused a pronounced increase in the bonding strength of the coating. The bonding strength between the coating and the substrate increased by $12.9 \%$ after the heat treatment at $600{ }^{\circ} \mathrm{C}$ in comparison with that of the as-sprayed coating. Moreover, in the case of heat treatment at $800{ }^{\circ} \mathrm{C}$ and $1000{ }^{\circ} \mathrm{C}$, a rupture occurred at the glue joint, indicating that the adhesion strength was higher than the value obtained. 


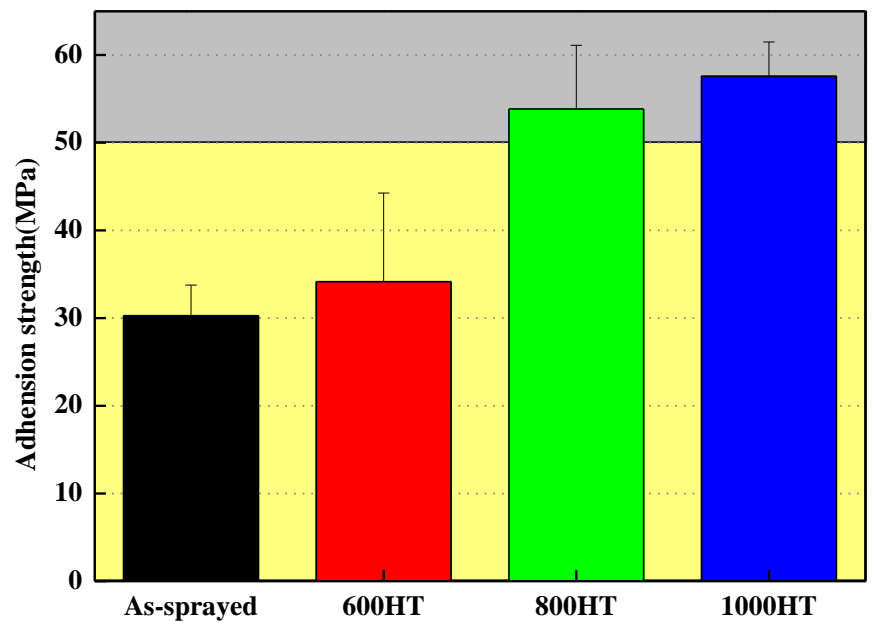

Fig.7 Adhesion strength for as-sprayed and heat-treated coatings

The morphology of the tensile failure section of the coating after the heat treatment at $600{ }^{\circ} \mathrm{C}$ is shown in Fig. 8. It can be seen that most of the particles maintained a spherical morphology for less severe deformation due to the relatively low gas temperature [45]. There are a large number of pores between the particles. The magnified image of the micro-region revealed that the fracture mainly occurred at the interface between the particles, which indicated that the adhesion strength was higher than the cohesion strength. On further enlargement, it was observed that a shear lip was formed at the interface of two particles due to the severe impact during the deposition; and no apparent necking phenomenon was observed, which indicated that the diffusion was weak at this temperature $[28,43]$.
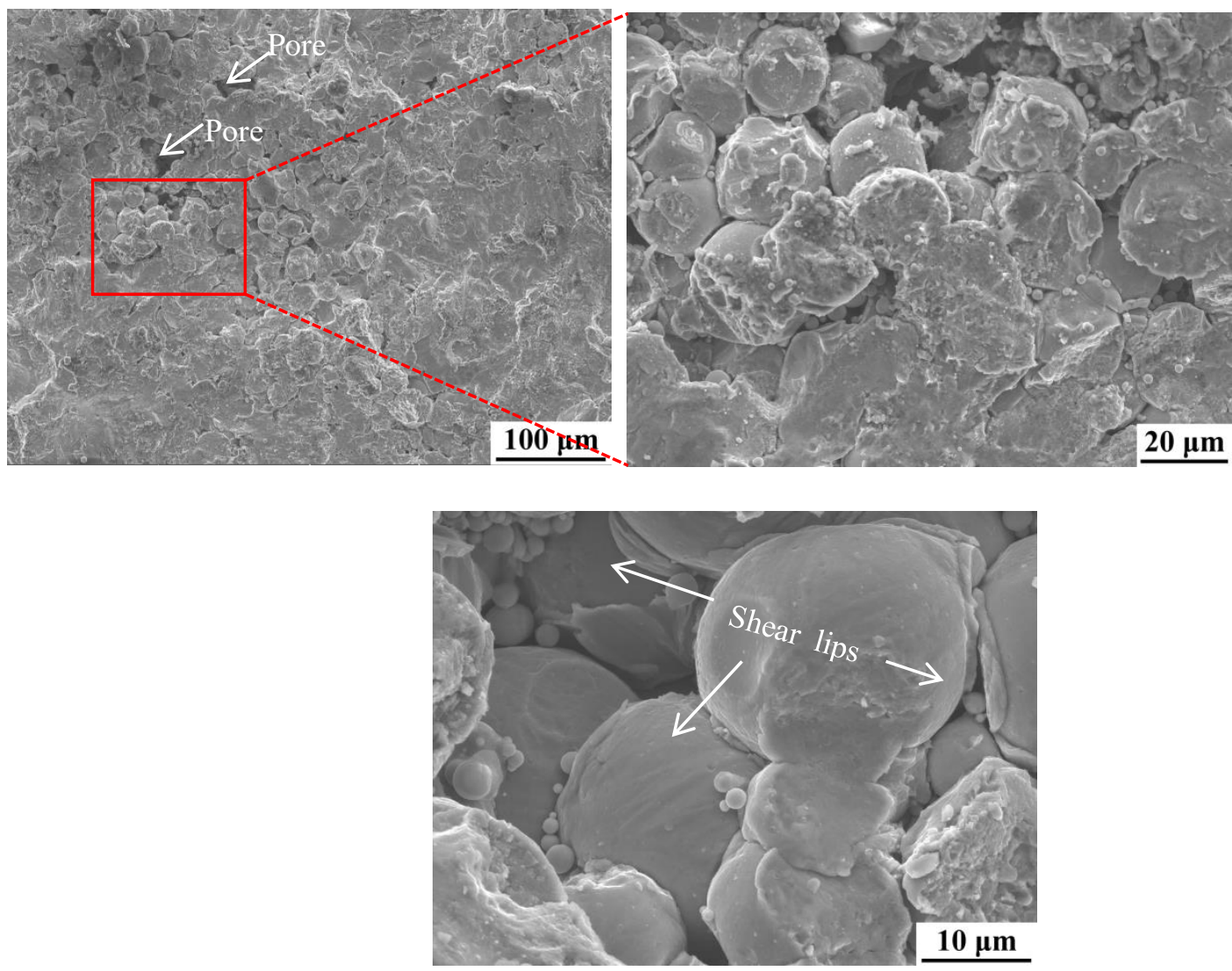

Fig. 8 Fracture morphology after heat treatment at $600^{\circ} \mathrm{C}$ 
Fig. 9 shows an interface microstructure between the as-sprayed and heat-treated TC4 coatings and the commercial TC4 substrate. It can be seen that the spherical particles are clearly visible in the as-sprayed coating, and the interface between the coating and the substrate can be easily identified, with a slight gap between them. After being heat-treated at $600{ }^{\circ} \mathrm{C}$, a similar cross-sectional microstructure is observed in which individual particles are locally visible. However, the interfacial gap between the coating and substrate is a little narrower as compared to that of the as-deposited coating. This implied that the heat treatment at $600{ }^{\circ} \mathrm{C}$ resulted in a slight diffusion between the coating and substrate[8,34]. When the temperature was increased to $800{ }^{\circ} \mathrm{C}$, the microstructure of the coating was completely different from the coating heat treated at $600{ }^{\circ} \mathrm{C}$. Due to the recrystallization of the sprayed particles, the grown equiaxed grains with a distinct two-phase structure was seen in the coating. The gaps in the interface disappeared due to a pronounced diffusion between the coating and the substrate. When the temperature was increased to $1000{ }^{\circ} \mathrm{C}$, more larger grains appeared in the cross-sectional microstructure via grain growth [8]; A complete interfacial mixing as well as small pores were found. When the interface was further enlarged, a lot of columnar crystals that grew from the substrate into the coating was observed, which further proved that sufficient diffusion occurred between the substrate and the coating. Although it was difficult to detect the interdiffusion of elements between the substrate and the coating as the main chemical composition of the two was the same in this study, it can be concluded that the bonding between them was enhanced due to high temperature diffusion. 

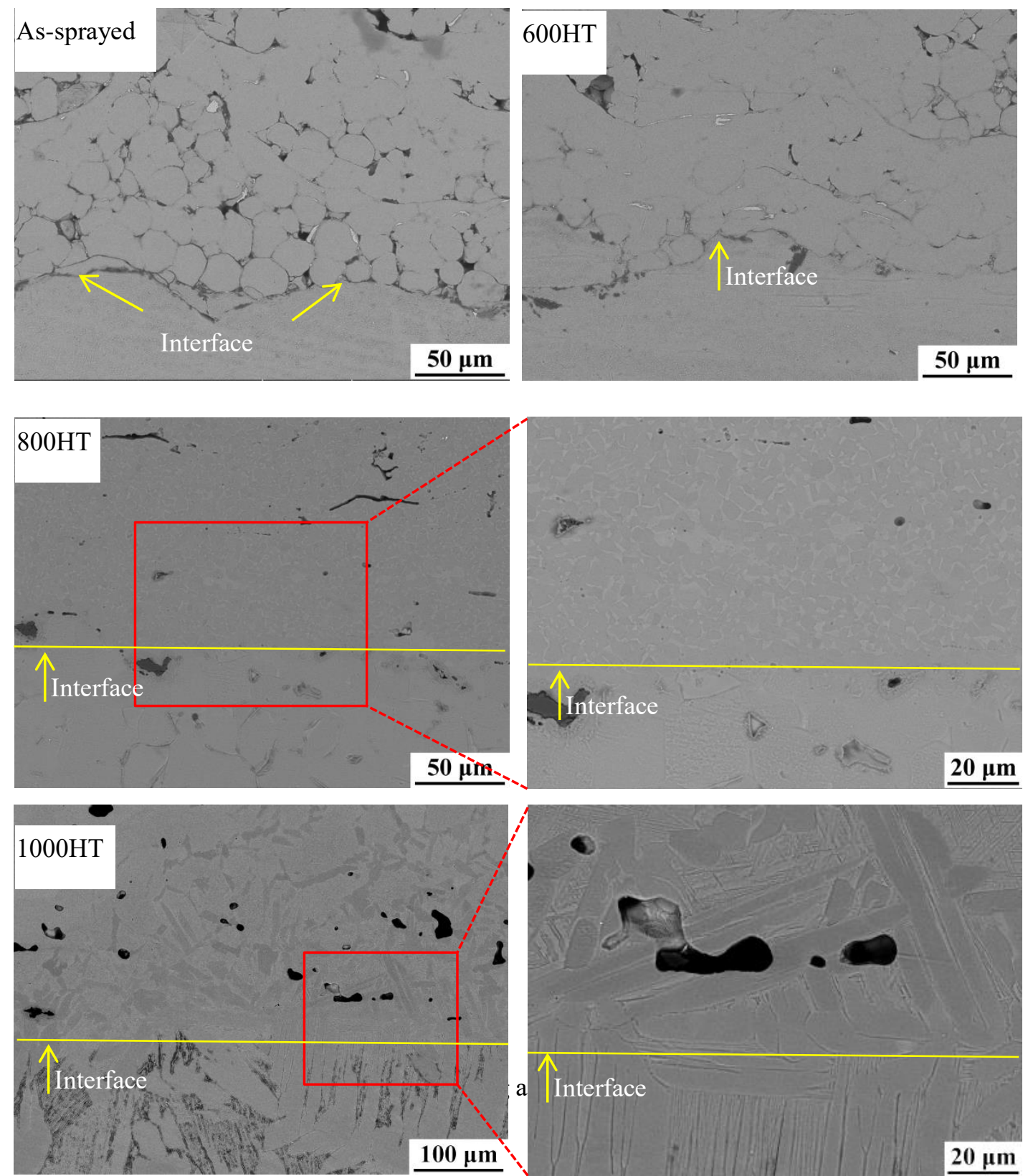

Engineering stress-strain curves for the as-sprayed and annealed coatings are shown in Fig. 10. It can be noted that the flow curves generally exhibited brittle failure, with only minor plastic deformation obtained after annealing at $600{ }^{\circ} \mathrm{C}$ and $800{ }^{\circ} \mathrm{C}$. Due to small sample geometry and limited process stability, the standard deviations obtained were $\sim 38 \mathrm{MPa}$ and $\sim 52 \mathrm{MPa}$ for heat-treated coating at $600{ }^{\circ} \mathrm{C}$ and $800{ }^{\circ} \mathrm{C}$, respectively. However, this phenomenon was consistent with the other reports of tensile test error values in cold spray $\mathrm{Cu}[46], \mathrm{Ni}[47]$, and Ti[34] coatings. For the coating obtained after annealing at $600{ }^{\circ} \mathrm{C}$, which was similar to the as-sprayed coating, the strength and ductility increased by $22.3 \%$ and $22.6 \%$, respectively. However, when the annealing temperature was increased to $800{ }^{\circ} \mathrm{C}$, a larger increase in strength up to a value of $316.46 \mathrm{MPa}$ with a failure strain of $0.54 \%$ was obtained. However, the sample heat-treated at $1000{ }^{\circ} \mathrm{C}$ was fractured during the preparation process. Subsequently, combined with a fracture analysis, it was concluded that the coating strength did not continue to increase with an increase in the heat treatment temperature. The reason for this is discussed in the following section. In comparison with the minimum ASTM values for Ti-6Al-4V forgings of $895 \mathrm{MPa}$ tensile strength and $10 \%$ elongation, it was the weak inter-particle strength and low area of inter-particle bonding that reduced the strength of 
the coating [34].

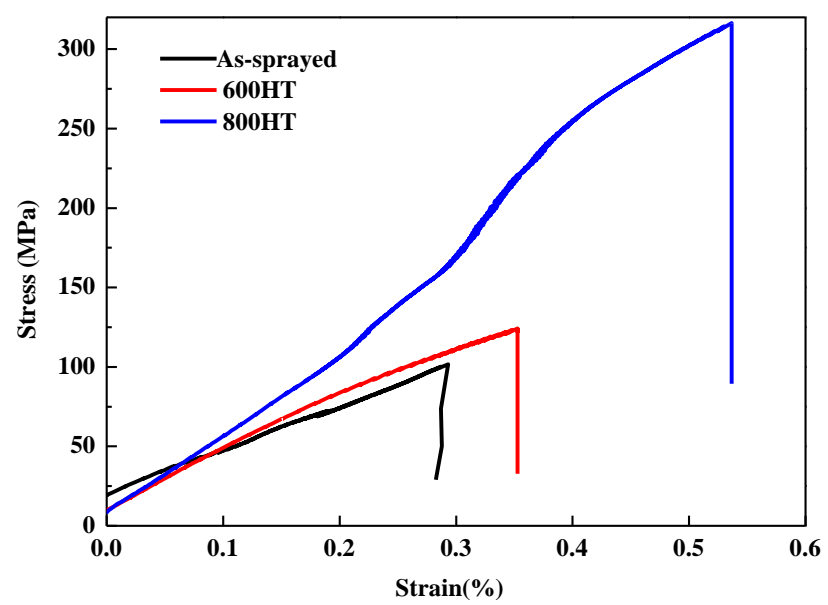

Fig. 10 Stress-strain curves for as-sprayed and heat-treated TC4 coating

Typical fracture surfaces of the tensile specimens for as-sprayed and for different annealing conditions are shown in Fig. 11-Fig. 14. Fig. 11 showed the fracture surface of the as-sprayed tensile specimen. As seen in Fig. 11(a), the coating is fractured in a brittle manner, and there are a large number of spherical particles on the fractured surface, which indicates that the deformation of the particles is limited during the impact. Moreover, there are considerable pores between the particles. On magnifying the image as shown in Fig. 11(b), it is observed that the coating fracture mainly occurs between the particles. Further enlargement, as shown in Fig. 11(c), reveals that a viscous flow is formed during the impact and a gap is formed between the two particles that is caused by the crack initiation and expansion during stretching. Fracture surfaces of tensile specimens after annealing at $600{ }^{\circ} \mathrm{C}$ is shown in Fig. 12. It can be noted that the coating microstructure is very similar to the as-sprayed one. The coating fracture still mainly occurs between the particles as seen in Fig. 12(a). On further enlargement, it can be seen that there is no obvious necking between the two particles, and only a few dimples on the interparticle rupture surface is observed, which is similar to the condition of the as-sprayed coating reported in a previous study [25]. This indicated that the diffusion was limited for the heat treatment at $600{ }^{\circ} \mathrm{C}$, and the proportion of metallurgical bonding between the particles did not increase significantly, which was consistent with the conclusion derived earlier. The fracture morphology of the tensile specimen after annealing at $800{ }^{\circ} \mathrm{C}$ is shown in Fig. 13 . Although many spherical particles are still visible at low magnification, it can be seen from the local enlargement that the coating structure has changed significantly as compared to that of the as-sprayed and heat-treated (at $600{ }^{\circ} \mathrm{C}$ ) coatings. The most conspicuous change is that a large number of dimples can be seen on the fractured surface, indicating that the metallurgical bonding between the particles is greatly enhanced at this temperature and the coating exhibits some ductility; in addition, at low magnification (Fig. 13(a)), a region sandwiched by the straight line can be seen, where the coating is very dense and no pores are present. Since the coating was prepared using the in-situ shot peening-assisted cold spray method, the particle deformation was enhanced by the shot peening particles and the pores almost disappeared in these regions. It was presumed that the sandwiched region was where the deposits were tamped by the shot peening particles, and the particle interfaces in this area completely disappeared after the heat treatment. Hence, the non-interparticle fracture occurred here instead, which was completely different from the interparticle fracture observed in the other areas (Fig. 13(b)). It was speculated that these non-interparticle fractured regions created a cross-linked network in the coating structure, which improved the tensile strength of the coating. On further magnifying the morphology as shown in Fig. 13(c) and 13(d), 
significant necking and interconnection of particles can be observed. The dimples seen in Fig. 13(c) may be the pit left after being pulled out of the grown recrystallized grains [48]. Fig. 14 shows the fracture surfaces of tensile specimens after annealing at $1000{ }^{\circ} \mathrm{C}$. It can be seen from Fig. 14(a) that the microstructure of the annealed coating is further different from the previous groups, and no large pores can be observed and the coating is much denser. However, the morphology of the spherical particles are still locally visible. In addition, there are hardly any dimples on the fractured surface, and the quasi-cleavage fracture pattern is observed instead, which greatly reduces the plasticity of the coating. This phenomenon was also reported in the study of cold-sprayed TC4 and A380 aluminum alloy coatings [34,49]. In Fig. 14(c), the spheroidized pores, which are caused by the sintering effect, are visible. In Fig. 14(d), it can be seen that the necking between the particles is more severe, which is a sign of an intense high temperature diffusion, and the pores between them have disappeared.
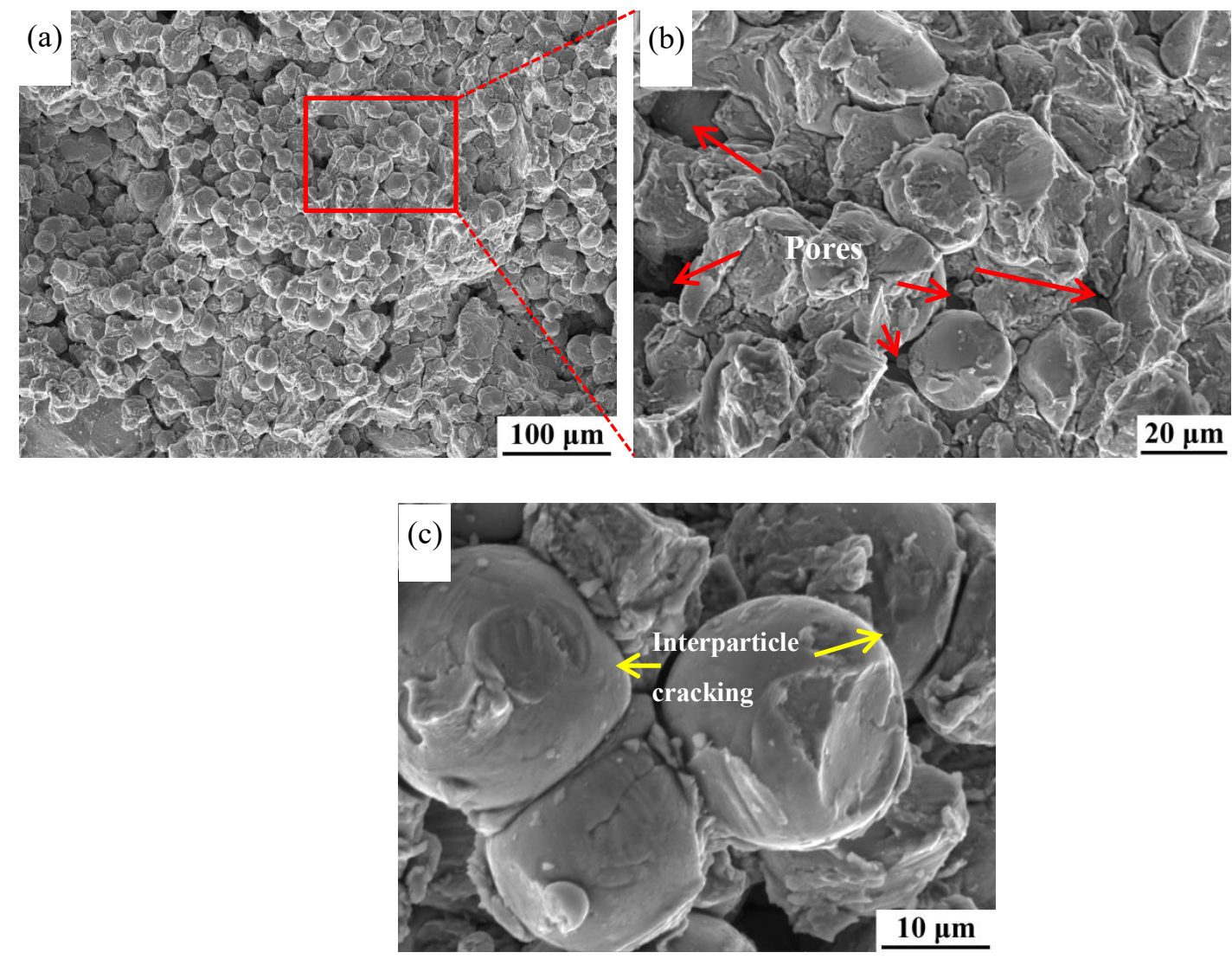

Fig.11 Fracture surfaces of tensile specimens for as-sprayed coating
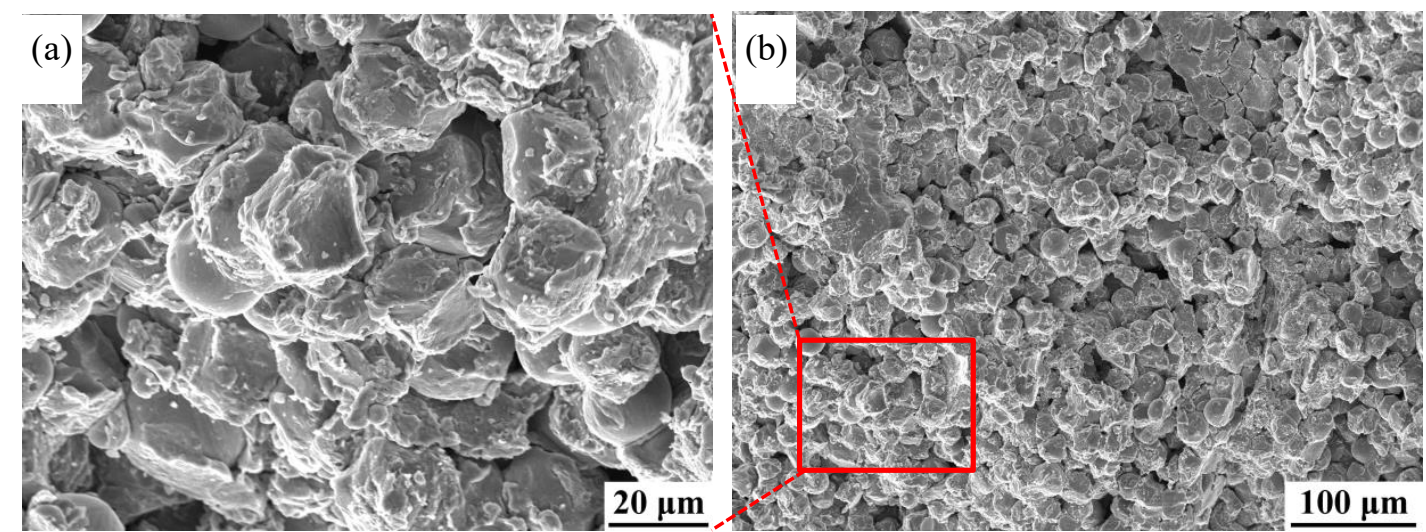

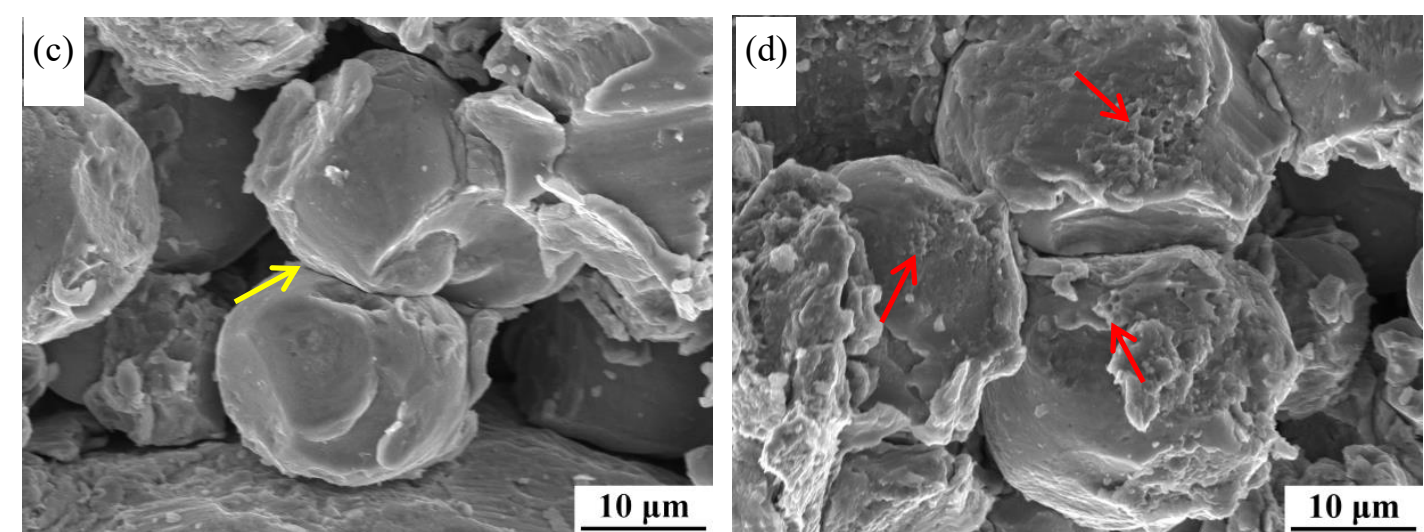

Fig. 12 Fracture surfaces of tensile specimens after $600^{\circ} \mathrm{Cheat}$ treatment
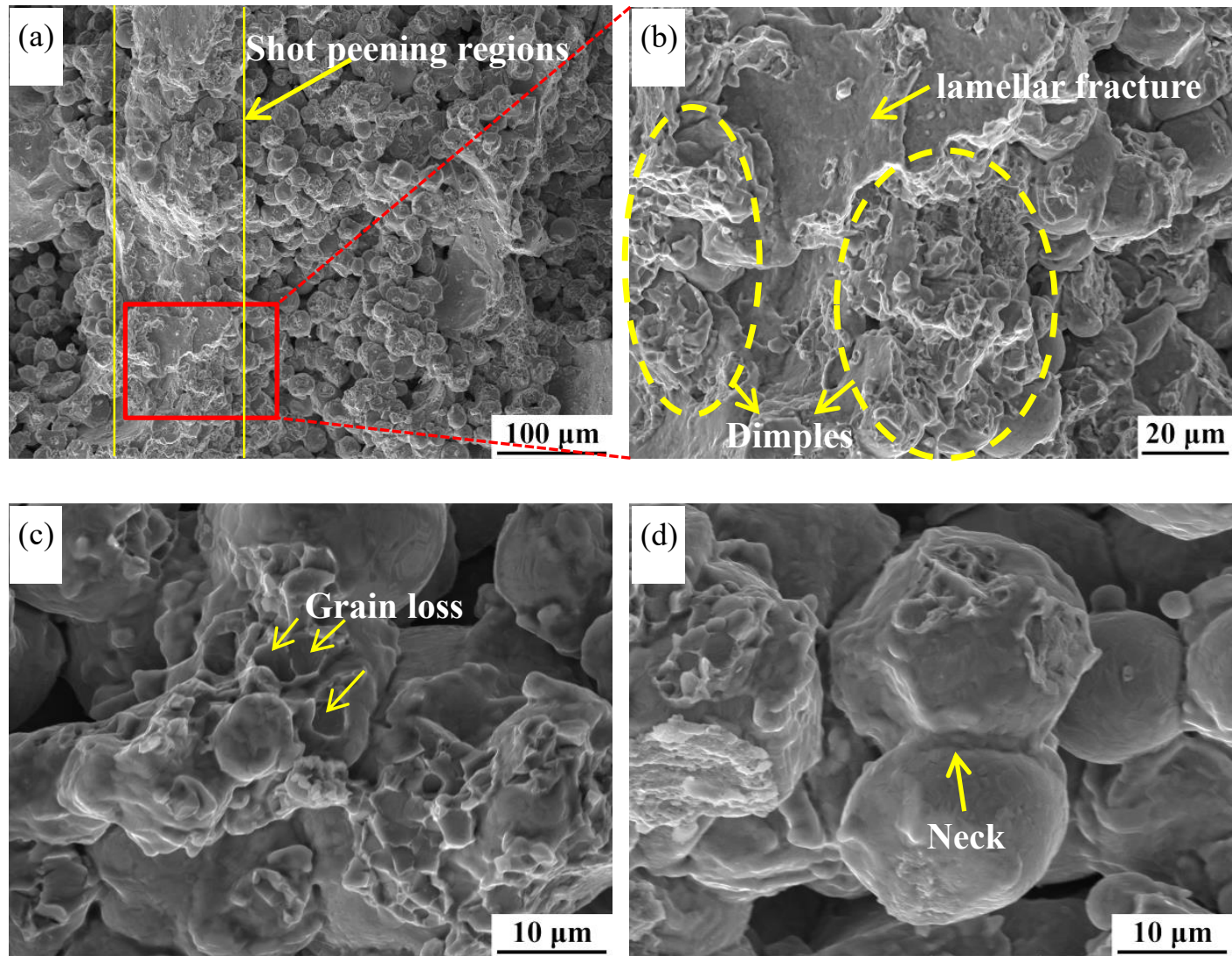

Fig.13 Fracture surfaces of tensile specimens after $800^{\circ} \mathrm{C}$ heat treatment
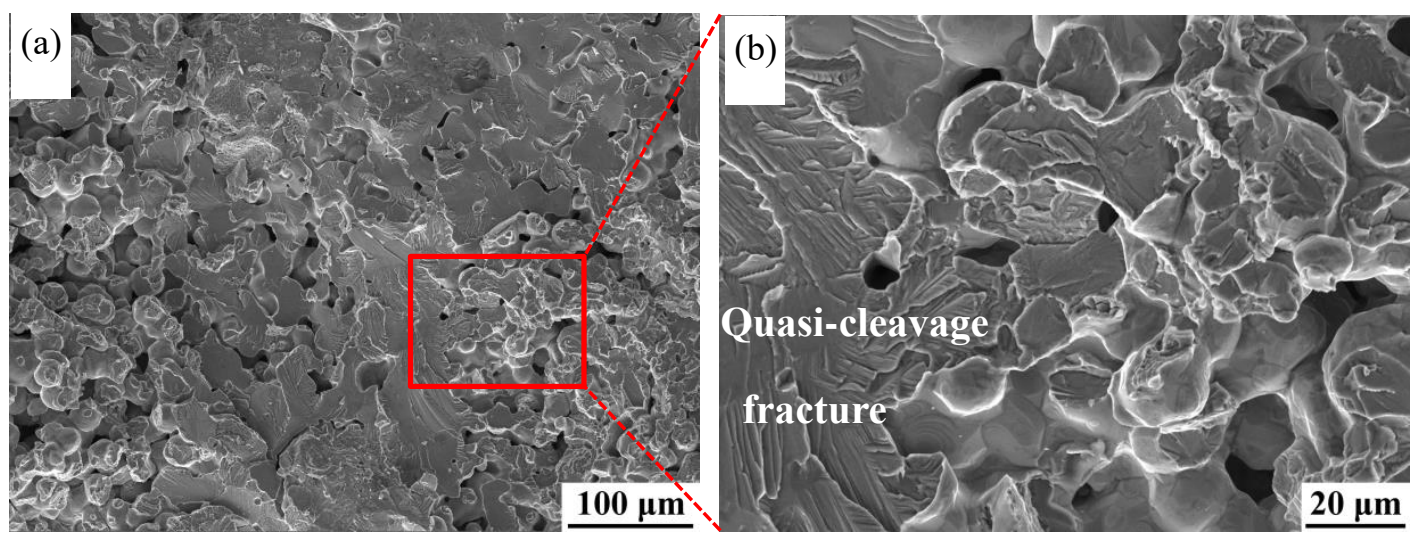

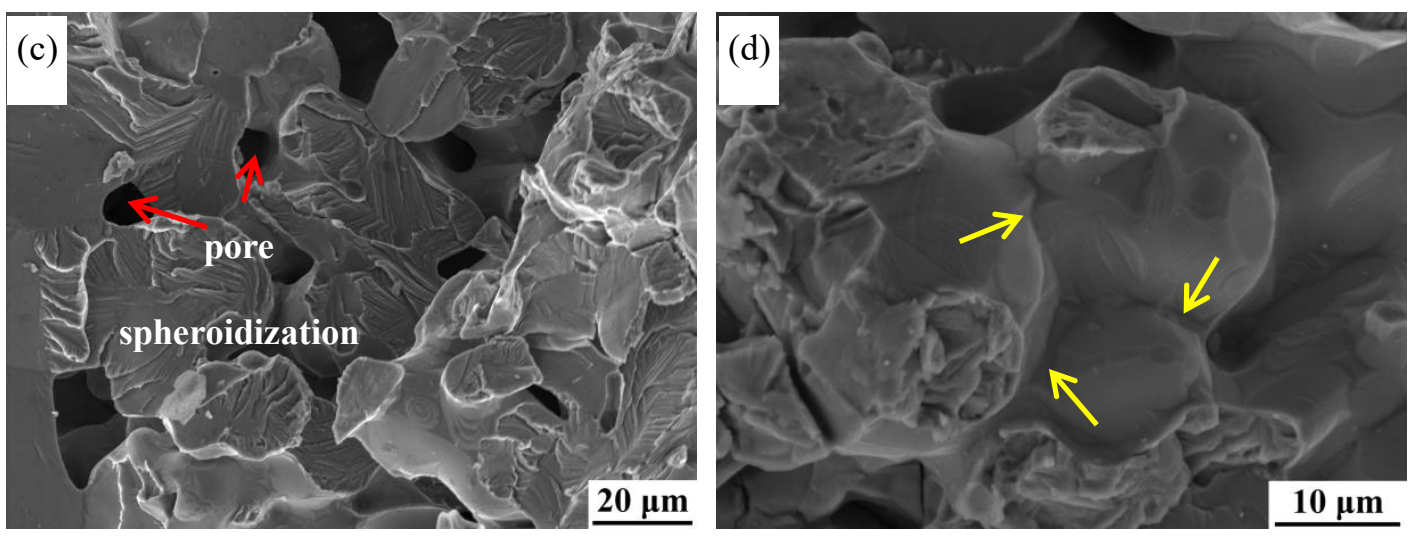

Fig. 14 Fracture surfaces of tensile specimens after $1000^{\circ} \mathrm{Cheat}$ treatment

\section{Discussion}

\subsection{Improvement of the mechanical properties of the coating induced by heat treatment}

There are two ways to strengthen metal materials. The first is to improve the interatomic bonding force of the alloy to improve the theoretical strength. The second is to introduce a large number of defects into the crystal, which hinders the movement of dislocations, thereby increasing the strength. The coating prepared using cold spraying process is formed by the continuous impact of high-speed powder. It is generally accepted that the adiabatic shear instability of the particles/substrate interfacial region results in the particle/substrate adhesion and particle/particle cohesion [50]. Although a large number of dislocations are formed during the high-speed impact of the particles, the cohesion between the particles is mainly based on the mechanical bonding. In a typical cold spray coating, only a fraction of the splats is well-bonded with the neighboring splats. Further, the unbonded or cracked splats as well as the pores formed between the particles have considerable influence on the performance of the cold-sprayed coatings $[35,51]$. Therefore, the heat treatment after spraying can improve the mechanical properties of the coating by enhancing the metallurgical bond and eliminating the pores between the particles in the coating.

Diffusion was considered to be the bonding mechanism for the post cold spray annealing process. Diffusion bonding generally occurs at temperatures of $0.5-0.8 \mathrm{Tm}$ [34,52]. For the titanium alloy, 0.5-0.8 Tm represents the temperature range $800-1300{ }^{\circ} \mathrm{C}$, which was consistent with the results that no further dimples were observed on the fractural surface for coatings heat-treated below $800{ }^{\circ} \mathrm{C}$. However, when the temperature exceeded $800{ }^{\circ} \mathrm{C}$, more metallurgical bonds were formed at the interface of the particles, even at the unbounded interface. At the same time, the porosity of the coating decreased significantly. According to the statistics, the porosity of the as-sprayed coating, heat-treated coatings at $600{ }^{\circ} \mathrm{C}, 800{ }^{\circ} \mathrm{C}$ and $1000{ }^{\circ} \mathrm{C}$ were $7.10 \%, 6.80 \%, 3.17 \%$ and $2.83 \%$, respectively. The post cold spray heat treatment caused the interface between the two particles to heal by high-temperature thermal diffusion, and the pores spheroidized and disappeared due to the sintering effect. Finally, the strength and toughness of the coating were improved.

\subsection{Microstructure evolution of 3D densified framework}

As seen in Fig. 10, the tensile strength of the coating is greatly improved after heat-treatment at $800{ }^{\circ} \mathrm{C}$, which is approximately twice as compared to that of the as-sprayed coating, and is much higher 
than the value reported in a previous literature [34]. The reason can be obtained from microstructure evolution of the in-situ shot peened coating after heat treatment. Fig. 15 shows the microstructure of the coating before and after annealing at $800{ }^{\circ} \mathrm{C}$. It can be seen clearly that the as-sprayed coating exhibits a special structure in which the particle deformation is more severe at the regions tamped by shot peening particles while the deformation is less in nontamped regions (Details about the as-sprayed TC4 coating prepared by in-situ shot peening assisted cold spraying can be referred elsewhere[25]). Moreover, there are regions where the craters interconnected to each other, and thus it forms a cross-linked dense deposit, which is indicated by a dotted line. In this cross-linked dense region, the deformation of the particles was violent and the flattening ratio increased nearly as much as three times as estimated above. Though the contact area between severely deformed particles had increased, the interface between the particles was still visible, which indicated that the metallurgical bonding was still limited. Thus, the strength of the in-situ shot peened as-sprayed coating did not increase significantly. However, the situation changed after high-temperature heat treatment. Due to the diffusion at high temperature, the bonding state between the particles in the coating was greatly improved, especially in the cross-linked dense region where the particles were closer to each other and the diffusion would occur more easily. Consequently, apart from the nontamped regions, the particle interface and pores completely disappeared (only left the spheroidized micropores as indicated by the arrows); the particles were completely fused with each other and the microstructure became similar to the bulk as the fractural morphology shown in Fig. 13(a) and 13(b). In this way, the coating was characterized by cross-linked microstructure of high-densification, and it was these high-densified regions that had a good ability to transmit the load and reduce the crack propagation rate. Hence, the coating exhibited a non-interparticle fracture (Fig. 13(b)) that was completely different from the typical fracture pattern of the other coatings that was mainly dominated by interparticle fracture in the tensile test. It was speculated that these highly-densified regions acted as 3D densified framework throughout the coating, which resulted in a significant increase in the coating strength. The schematic diagram revealing the formation of 3D densified framework during heat treatment is shown in Fig. 16.
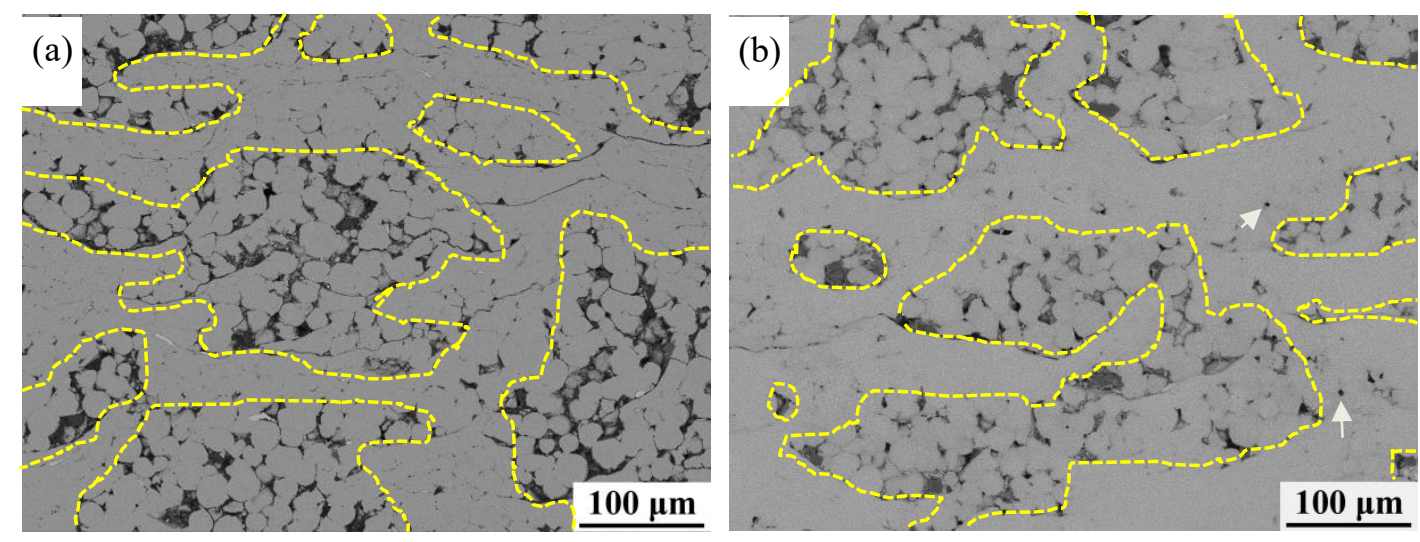

Fig. 15 Microstructure of the coating before (a) and after annealed at $800^{\circ} \mathrm{C}(\mathrm{b})$ 


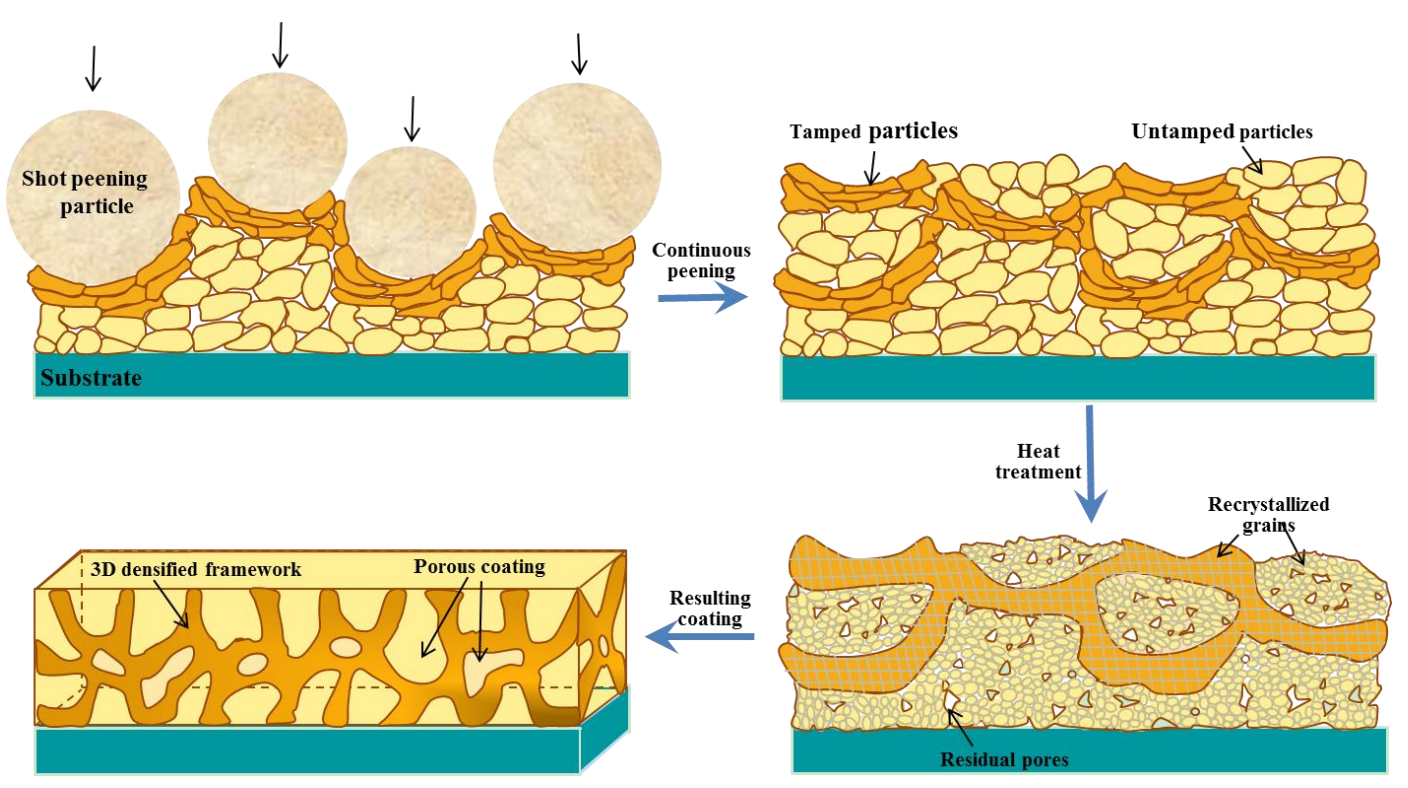

Fig. 16 Schematic diagram of formation of locally high-densification regions

during heat treatment

\subsection{Strength mechanism of cold sprayed TC4 coating during heat treatment}

As mentioned above, the metallurgical bonding in the coating increased after heat treatment at $800{ }^{\circ} \mathrm{C}$, and a large number of dimples appeared on the fractured surface. However, the strength and toughness of the coating did not increase continuously with the increase in heat treatment temperature. In this study, two sets of samples were prepared for tensile strength test after heat treatment at $1000{ }^{\circ} \mathrm{C}$. However, without any exception, the fracture occurred during the sample preparation process. Therefore, it can be concluded that the strength of the coating was not high. Moreover, as seen in Fig. 14, the fracture morphology of the coating changes from a ductile manner after the heat treatment at $800{ }^{\circ} \mathrm{C}$ to a quasi-cleavage feature after the heat treatment at $1000{ }^{\circ} \mathrm{C}$. Since the coating recrystallizes at $700{ }^{\circ} \mathrm{C}$, recrystallized grain growth inevitably took place at higher temperature, and previous studies have shown that the growth of recrystallized grains at very high temperatures leads to a decrease in yield strength and tensile strength $[49,53]$. To determine the reason, EBSD was used to analyze the evolution of grain size during $700-1000{ }^{\circ} \mathrm{C}$ heat treatment. As shown in Fig. 17, a large number of tiny recrystallized grains appear after heat treatment at $700{ }^{\circ} \mathrm{C}$, which was partially growing during the subsequent heat treatment. As the temperature increased, the local growth of the grain gradually evolved into a uniform growth. Fig. 18 shows the grain size of $\alpha$ and $\beta$ phase after different heat treatments. According to statistics, the grain size of most of the $\alpha$ and $\beta$ phase in the coating exceeded $1 \mu \mathrm{m}$ at $1000^{\circ} \mathrm{C}$, while most of grains were under $1 \mu \mathrm{m}$ at $700{ }^{\circ} \mathrm{C}, 800{ }^{\circ} \mathrm{C}$ and $900{ }^{\circ} \mathrm{C}$. Known by the Hall-Petch formula [54], the increase in grain size results in a decrease in material strength. On the other hand, for titanium alloy, $1000{ }^{\circ} \mathrm{C}$ is close to the transition temperature (approximately $1155 \mathrm{~K}$ ) from $\alpha$ phase to $\beta$ phase [55]. From the phase map shown in Fig. 17, it can also be observed that as the heat treatment temperature increases, the $\beta$ phase formed in the grain boundary of the $\alpha$ phase gradually increases. According to statistics, the $\beta$ phase content in the analytical range after the heat treatment at $700{ }^{\circ} \mathrm{C}, 800{ }^{\circ} \mathrm{C}, 900{ }^{\circ} \mathrm{C}$, and $1000{ }^{\circ} \mathrm{C}$ was $13.1 \%, 14.9 \%$, $16.27 \%$, and $25.1 \%$, respectively. The $\beta$ phase was generated most at $1000{ }^{\circ} \mathrm{C}$. Since the degree of atomic 
arrangement in the $\alpha$ phase (HCP) structure was larger than that in the $\beta$ phase (BCC), the diffusion in the $\beta$ phase was faster than that in the $\alpha$ phase [56], which helped in the change of the microstructure and growth of the recrystallized grains at this temperature [57]. Moreover, due to the presence of large number of the $\beta$ phases, the plasticity of the coating was enhanced, and the strength was inevitably lowered. Based on this result, to obtain higher strength, it may be better to heat-treat titanium alloy coating under $1000{ }^{\circ} \mathrm{C}$.
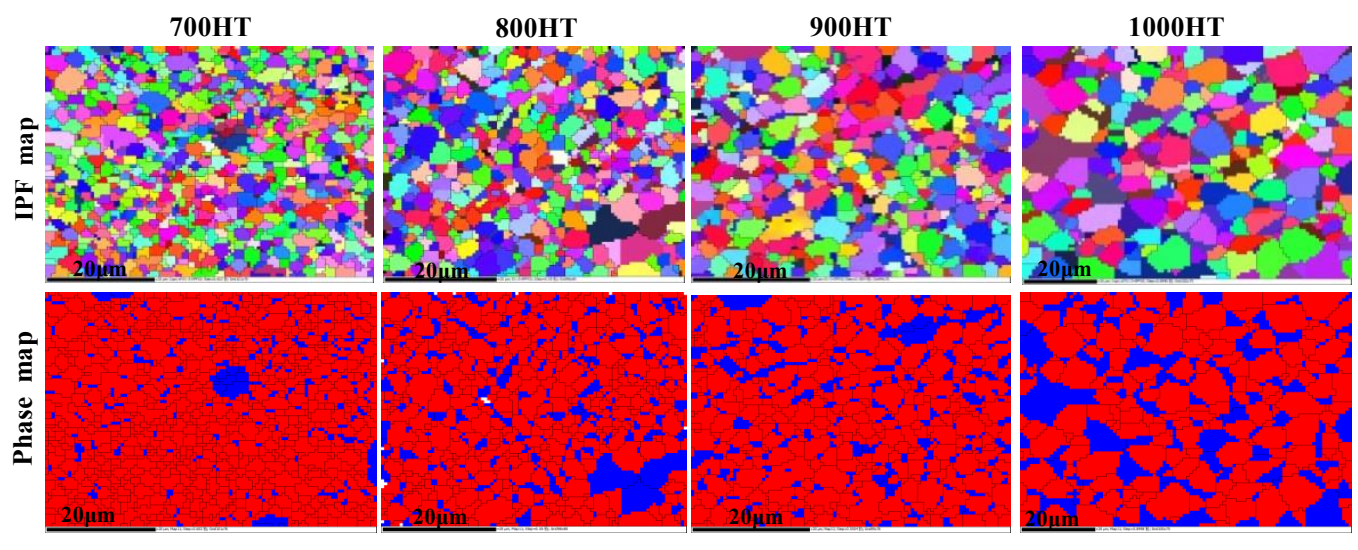

Fig.17 EBSD micrograph of the coating after different heat treatment temperature

(Red is $\alpha$ and blue is $\beta$ in the phase map)

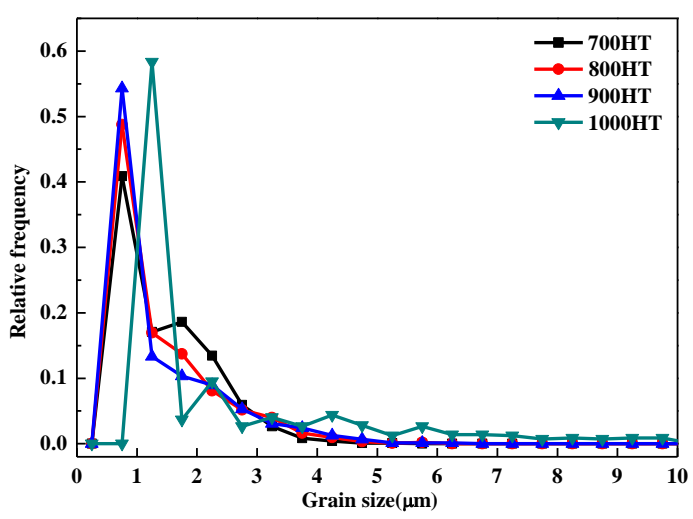

(a)

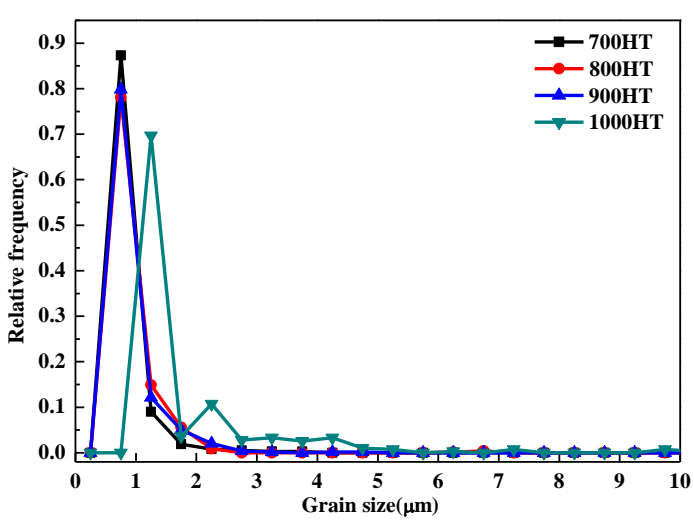

(b)

Fig. 18 Grain size of $\alpha$ (a) and $\beta$ (b) phase after different heat treatment temperature

\section{Conclusions}

In this study, TC4 coating was prepared using the in-situ shot peening-assisted cold-sprayed technology and heat-treated at $600{ }^{\circ} \mathrm{C}, 800{ }^{\circ} \mathrm{C}$, and $1000{ }^{\circ} \mathrm{C}$. The effect of heat treatment on the microstructure and mechanical properties was systematically investigated. The results demonstrated that as-sprayed coating exhibited a special microstructure featured by alternating dense and porous regions. Particle deformation in the regions impacted by large shot-peening particles was more severe in comparison with that in the other regions, and the particles boundaries were visible in the coating. The heat treatment below $800{ }^{\circ} \mathrm{C}$ caused recrystallization such that new fine grains were developed in the coating, and the heat treatment at $1000{ }^{\circ} \mathrm{C}$ resulted in significant changes in the coating structure. The heat treatment temperature from $600{ }^{\circ} \mathrm{C}$ to $800{ }^{\circ} \mathrm{C}$ decreased the hardness of the coating probably due to the degraded cold-worked microstructure of 
the coating. However, the coating hardness increased after annealing at $1000{ }^{\circ} \mathrm{C}$ due to the formation of an $\alpha^{\prime}$ martensitic phase during the rapid cooling from $1000{ }^{\circ} \mathrm{C}$ to room temperature. The adhesion strength of the coating increased after annealing at $800{ }^{\circ} \mathrm{C}$ and $1000{ }^{\circ} \mathrm{C}$, and the interface between the coating and the substrate disappeared due to the effect of thermal diffusion. The tensile strength test results demonstrated that the strength of the coating increased significantly after the heat treatment at $800{ }^{\circ} \mathrm{C}$. A large number of dimples in the fractural morphology indicated that metallurgical bonding increased during the heat treatment. In contrast, the inter-connection of the local regions, tamped by the shot peening particles, were sintered and formed a high-densified network during the heat treatment. This acted as the cross-linked 3D densified framework in the coating, and hence, the strength of the coating significantly increased. Nonetheless, the EBSD analysis revealed that the formation of larger grains in the coating via the growth of recrystallized grains and the formation of some $\beta$ phases after the heat treatment at $1000{ }^{\circ} \mathrm{C}$ resulted in a decrease in the coating strength.

\section{Acknowledgements}

The authors would like to thank the financial support by the National Science Fund of China (No.51761145108).

\section{References}

1. M. Peters, J. Kumpfert, C.H. Ward, C. Leyens, Titanium Alloys for Aerospace Applications (p\&nbsp;419-427), Advanced Engineering Materials, 5(6), 419-427 (2010)

2. R.R. Boyer, An overview on the use of titanium in the aerospace industry, Materials Science \& Engineering A, 213(1-2), 103-114 (1996)

3. M. Peters, J. Hemptenmacher, J. Kumpfert, C. Leyens, Structure and Properties of Titanium and Titanium Alloys, Wiley - VCH Verlag GmbH \& Co. KGaA, 2003

4. A.M. Birt, V.K. Champagne, R.D. Sisson, D. Apelian, Microstructural Analysis of Cold-Sprayed Ti-6Al-4V at the Micro- and Nano-Scale, Journal of Thermal Spray Technology, 24(7), 1277-1288 (2015)

5. S.H. Zahiri, C.I. Antonio, M. Jahedi, Elimination of porosity in directly fabricated titanium via cold gas dynamic spraying, Journal of Materials Processing Technology, 209(2), 922-929 (2009)

6. K. Kim, S. Kuroda, M. Watanabe, R. Huang, H. Fukanuma, H. Katanoda, Comparison of Oxidation and Microstructure of Warm-Sprayed and Cold-Sprayed Titanium Coatings, Journal of Thermal Spray Technology, 21(3-4), 550-560 (2011)

7. T. Hussain, D.G. McCartney, P.H. Shipway, T. Marrocco, Corrosion Behavior of Cold Sprayed Titanium Coatings and Free Standing Deposits, Journal of Thermal Spray Technology, 20(1-2), 260-274 (2010)

8. S.H. Zahiri, D. Fraser, M. Jahedi, Recrystallization of Cold Spray-Fabricated CP Titanium Structures, Journal of Thermal Spray Technology, 18(1), 16-22 (2008)

9. A.M. Birt, V.K. Champagne, R.D. Sisson, D. Apelian, Microstructural analysis of Ti-6Al - 4V powder for cold gas dynamic spray applications, Advanced Powder Technology, 26(5), 1335-1347 (2015)

10. D.I. Adebiyi, A.P.I. Popoola, I. Botef, Low pressure cold spray coating of Ti-6Al-4V with SiC-based 
cermet, Materials Letters, 175, 63-67 (2016)

11. G.-R. Li, L.-S. Wang, Durable TBCs with self-enhanced thermal insulation based on co-design on macro-and microstructure, Applied Surface Science, (2019)

12. M.R. Rokni, C.A. Widener, S.P. Ahrenkiel, B.K. Jasthi, V.R. Champagne, Annealing behaviour of 6061 aluminium deposited by high pressure cold spray, Surface Engineering, 30(5), 361-368 (2014)

13. M.R. Rokni, C.A. Widener, G.A. Crawford, M.K. West, An investigation into microstructure and mechanical properties of cold sprayed 7075 Al deposition, Materials Science \& Engineering A, 625, 19-27 (2015)

14. C. Borchers, F. Gartner, T. Stoltenhoff, H. Kreye, Microstructural bonding features of cold sprayed face centered cubic metals, Journal of Applied Physics, 96(8), 4288-4292 (2004)

15. M. Fukumoto, M. Mashiko, M. Yamada, E. Yamaguchi, Deposition Behavior of Copper Fine Particles onto Flat Substrate Surface in Cold Spraying, Journal of Thermal Spray Technology, 19(1-2), 89-94 (2010)

16. X.T. Luo, C.X. Li, F.L. Shang, G.J. Yang, Y.Y. Wang, C.J. Li, High velocity impact induced microstructure evolution during deposition of cold spray coatings: A review, Surface \& Coatings Technology, 254(10), $11-20$ (2014)

17. W.-Y. Li, C. Zhang, X. Guo, J. Xu, C.-J. Li, H. Liao, C. Cocidet, K.A. Khor, Ti and Ti-6Al-4V coatings by cold spraying and microstructure modification by heat treatment, Advanced Engineering Materials, 9(5), 418-423 (2007)

18. T. Marrocco, D.G. Mccartney, P.H. Shipway, A.J. Sturgeon, Production of titanium deposits by cold-gas dynamic spray: Numerical modeling and experimental characterization, Journal of Thermal Spray Technology, 15(2), 263-272 (2006)

19. P. Vo, D. Goldbaum, W. Wong, E. Irissou, J.G. Legoux, R.R. Chromik, S. Yue, Cold-spray processing of titanium and titanium alloys, 2015

20. H. Fukanuma, N. Ohno, A study of adhesive strength of cold spray coatings, 329-334 (2004)

21. R.E. Blose, B.H. Walker, R.M. Walker, S.H. Froes, New opportunities to use cold spray process for applying additive features to titanium alloys, Metal Powder Report, 61(9), 30-37 (2006)

22. N.W. Khun, A.W.Y. Tan, K.J.W. Bi, E. Liu, Effects of working gas on wear and corrosion resistances of cold sprayed Ti-6Al-4V coatings, Surface and Coatings Technology, 302, 1-12 (2016)

23. C.-J. Li, W.-Y. Li, Deposition characteristics of titanium coating in cold spraying, Surface and Coatings Technology, 167(2-3), 278-283 (2003)

24. X.-T. Luo, Y.-K. Wei, Y. Wang, C.-J. Li, Microstructure and mechanical property of Ti and Ti6Al4V prepared by an in-situ shot peening assisted cold spraying, Materials \& Design, 85, 527-533 (2015)

25. H. Zhou, C. Li, G. Ji, S. Fu, H. Yang, X. Luo, G. Yang, C. Li, Local microstructure inhomogeneity and gas temperature effect in in-situ shot-peening assisted cold-sprayed Ti-6Al-4V coating, Journal of Alloys and Compounds, 766, 694-704 (2018) 
26. Y.Q. Ren, P.C. King, Y.S. Yang, T.Q. Xiao, C. Chu, S. Gulizia, A.B. Murphy, Characterization of heat treatment-induced pore structure changes in cold-sprayed titanium, Materials Characterization, 132, 69-75 (2017)

27. N. Kang, P. Coddet, H. Liao, C. Coddet, Cold gas dynamic spraying of a novel micro-alloyed copper: Microstructure, mechanical properties, Journal of Alloys and Compounds, 686, 399-406 (2016)

28. W.-Y. Li, C. Yang, H. Liao, Effect of vacuum heat treatment on microstructure and microhardness of cold-sprayed TiN particle-reinforced Al alloy-based composites, Materials \& Design, 32(1), 388-394 (2011)

29. N. Kang, P. Coddet, H. Liao, C. Coddet, Cold gas dynamic spraying of a novel micro-alloyed copper: Microstructure, mechanical properties, Journal of Alloys \& Compounds, 686, 399-406 (2016)

30. W. Li, K. Yang, S. Yin, X. Yang, Y. Xu, R. Lupoi, Solid-state additive manufacturing and repairing by cold spraying: A review, Journal of Materials Science \& Technology, (3), (2018)

31. H. Assadi, H. Kreye, F. Gärtner, T. Klassen, Cold spraying - A materials perspective, Acta Materialia, 116, 382-407 (2016)

32. R.N. Raoelison, C. Verdy, H. Liao, Cold gas dynamic spray additive manufacturing today: Deposit possibilities, technological solutions and viable applications, Materials \& Design, (2017)

33. W. Wong, E. Irissou, J.G. Legoux, P. Vo, S. Yue, Powder Processing and Coating Heat Treatment on Cold Sprayed Ti-6Al-4V Alloy, Materials Science Forum, 2012, pp 258-263

34. P. Vo, E. Irissou, J.G. Legoux, S. Yue, Mechanical and Microstructural Characterization of Cold-Sprayed Ti-6Al-4V After Heat Treatment, Journal of Thermal Spray Technology, 22(6), 954-964 (2013)

35. G. Sundararajan, N.M. Chavan, S. Kumar, The Elastic Modulus of Cold Spray Coatings: Influence of Inter-splat Boundary Cracking, Journal of Thermal Spray Technology, 22(8), 1348-1357 (2013)

36. W.Y. Li, C. Zhang, X. Guo, J. Xu, C.J. Li, H. Liao, C. Coddet, K.A. Khor, Ti and Ti - 6Al - 4V Coatings by Cold Spraying and Microstructure Modification by Heat Treatment, Advanced Engineering Materials, 9(5), 418-423 (2007)

37. G. Bae, S. Kumar, S. Yoon, K. Kang, H. Na, H.J. Kim, C. Lee, Bonding features and associated mechanisms in kinetic sprayed titanium coatings, Acta Materialia, 57(19), 5654-5666 (2009)

38. H. Zhou, C. Li, H. Yang, X. Luo, G. Yang, W. Li, T. Hussain, C. Li, Pores Structure Change Induced by Heat Treatment in Cold-Sprayed Ti6Al4V Coating, Journal of Thermal Spray Technology, 28(6), 1199-1211 (2019)

39. B. Dikici, H. Yilmazer, I. Ozdemir, M. Isik, The Effect of Post-Heat Treatment on Microstructure of 316L Cold-Sprayed Coatings and Their Corrosion Performance, Journal of Thermal Spray Technology, 25(4), 704-714 (2016)

40. B. Al-Mangour, R. Mongrain, E. Irissou, S. Yue, Improving the strength and corrosion resistance of 316L stainless steel for biomedical applications using cold spray, Surface and Coatings Technology, 216, 297-307 (2013)

41. M.A. Garrido, P. Sirvent, P. Poza, Evaluation of mechanical properties of Ti6Al4V cold sprayed coatings, 
Surface Engineering, 34(5), 399-406 (2017)

42. Z. Arabgol, M. Villa Vidaller, H. Assadi, F. Gärtner, T. Klassen, Influence of thermal properties and temperature of substrate on the quality of cold-sprayed deposits, Acta Materialia, 127, 287-301 (2017)

43. N.W. Khun, A.W.Y. Tan, W. Sun, E. Liu, Effect of Heat Treatment Temperature on Microstructure and Mechanical and Tribological Properties of Cold Sprayed Ti-6Al-4V Coatings, Tribology Transactions, 60(6), 1033-1042 (2016)

44. A. Birt, V. Champagne, R. Sisson, D. Apelian, Microstructural analysis of cold-sprayed Ti-6Al-4V at the micro-and nano-scale, Journal of Thermal Spray Technology, 24(7), 1277-1288 (2015)

45. R.C. Dykhuizen, M.F. Smith, Gas dynamic principles of cold spray, Journal of Thermal Spray Technology, 7(2), 205-212 (1998)

46. F. Gärtner, T. Stoltenhoff, J. Voyer, H. Kreye, S. Riekehr, M. Koçak, Mechanical properties of cold-sprayed and thermally sprayed copper coatings, Surface \& Coatings Technology, 200(24), 6770-6782 (2006)

47. M.K. Decker, Microstructure and Properties of Cold Spray Nickel, Proc.itsc.singapore, 433, (2001)

48. G. Bae, K. Kang, J.-J. Kim, C. Lee, Nanostructure formation and its effects on the mechanical properties of kinetic sprayed titanium coating, Materials Science and Engineering: A, 527(23), 6313-6319 (2010)

49. X. Qiu, J.-q. Wang, L. Gyansah, J.-x. Zhang, T.-y. Xiong, Effect of heat treatment on microstructure and mechanical properties of A380 aluminum alloy deposited by cold spray, Journal of Thermal Spray Technology, 26(8), 1898-1907 (2017)

50. M. Grujicic, C.L. Zhao, W.S. DeRosset, D. Helfritch, Adiabatic shear instability based mechanism for particles/substrate bonding in the cold-gas dynamic-spray process, Materials \& Design, 25(8), 681-688 (2004)

51. K. Yang, W. Li, X. Yang, Y. Xu, Anisotropic response of cold sprayed copper deposits, Surface and Coatings Technology, 335, 219-227 (2018)

52. B. Derby, E.R. Wallach, Diffusion bonding: development of theoretical model, Metal Science Journal, 18(9), 427-431 (2013)

53. R. Huang, M. Sone, W. Ma, H. Fukanuma, The effects of heat treatment on the mechanical properties of cold-sprayed coatings, Surface and Coatings Technology, 261, 278-288 (2015)

54. A.W.-Y. Tan, W. Sun, Y.P. Phang, M. Dai, I. Marinescu, Z. Dong, E. Liu, Effects of Traverse Scanning Speed of Spray Nozzle on the Microstructure and Mechanical Properties of Cold-Sprayed Ti6Al4V Coatings, Journal of Thermal Spray Technology, 26(7), 1484-1497 (2017)

55. L. Zeng, T. Bieler, Effects of working, heat treatment, and aging on microstructural evolution and crystallographic texture of $\alpha, \alpha^{\prime}, \alpha{ }^{\prime \prime}$ and $\beta$ phases in Ti-6Al-4V wire, Materials Science and Engineering: A, 392(1-2), 403-414 (2005)

56. M. Peters, J. Hemptenmacher, J. Kumpfert, C. Leyens, Structure and properties of titanium and titanium alloys, Titanium and titanium alloys: fundamentals and applications, 1-36 (2003) 
57. B. Vrancken, L. Thijs, J.-P. Kruth, J. Van Humbeeck, Heat treatment of Ti6Al4V produced by Selective Laser Melting: Microstructure and mechanical properties, Journal of Alloys and Compounds, 541, 177-185 (2012) 